\title{
Pelatihan Microsoft Powerpoint Dasar Bagi Guru Guru Paud Kabupaten Bekasi
}

\author{
Muhammad Rusli ${ }^{1)}$, Edy Winarso' ${ }^{2)}$, Darani Putri ${ }^{\text {n) }}$ \\ Sistem Informasi, Fakultas Industri Kreatif, Institut Teknologi dan Bisnis kalbis \\ Jalan Pulomas Selatan KAV 22, Jakarta 13210 \\ ${ }^{1)}$ muhammad.rusli@kalbis.ac.id \\ ${ }^{2)}$ edywinarso@yahoo.com
}

\begin{abstract}
Based on the Vision and Mission of HIMPAUDI is "Being a professional and independent organization to realize PAUD Education and Education Staff who are competent, quality, and dignified by 2025" the Information Systems Study Program proposes to provide training "Microsoft Power Point Training for PAUD Teachers Bekasi Regency ". This training will greatly support and assist PAUD teachers to create educational documents, teaching materials and correspondence in order to improve the performance of teachers and develop teaching and learning activities in PAUD Bekasi Regency.
\end{abstract}

Keywords: PAUD, PKBM, PPT, Teacher

\begin{abstract}
Abstrak: Berdasarkan Visi dan Misi HIMPAUDI adalah "Menjadi Organisasi profesional dan mandiri untuk mewujudkan Pendidikan dan Tenaga Kependidikan PAUD yang kompeten, berkualitas, dan bermartabat pada tahun 2025" maka Prodi Sistem Informasi mengusulkan untuk memberikan pelatihan "Pelatihan Microsoft Power Point Bagi Guru-Guru PAUD Kabupaten Bekasi". Pelatihan ini akan sangat mendukung dan membantu guru-guru PAUD untuk membuat dokumen pendidikan, bahan pengajaran dan surat menyurat dalam rangka meningkatkan kinerja guru-guru dan pengembangan kegiatan belajar mengajar di PAUD Kabupaten Bekasi.
\end{abstract}

Kata kunci: Guru, PAUD, PKBM, PPT

\section{PENDAHULUAN}

Pendidikan anak usia dini (PAUD) adalah jenjang pendidikan sebelum jenjang pendidikan dasar yang merupakan suatu upaya pembinaan yang ditujukan bagi anak sejak lahir sampai dengan usia enam tahun yang dilakukan melalui pemberian rangsangan pendidikan untuk membantu pertumbuhan dan perkembangan jasmani dan rohani agar anak memiliki kesiapan dalam memasuki pendidikan lebih lanjut, yang diselenggarakan pada jalur formal, nonformal, dan informal (Suyadi, 2013).

Himpunan PAUD (HIMPAUDI) Kabupaten Bekasi memiliki 23 kecamatan, 187 kelurahan dan 176 desa yang memiliki PAUD. HIMPAUDI Kabupaten Bekasi berada di Jalan MT.Haryono No.26 Desa Taman Rahayu, Kecamatan Setu, Kabupaten Bekasi, Jawa Barat.

Dalam pelaksanaan kegiatan PAUD di Kabupaten Bekasi terdapat beberapa kendala yang dihadapi yaitu, dalam pengelolaan dokumen pendidikan, surat menyurat dalam kegiatan organisasi dan persiapan bahan ajar dalam proses belajar mengajar. Keterlibatan teknologi komputer sebagai alat untuk memudahkan suatu pekerjaan juga dapat meningkatkan efisiensi waktu dan tenaga dalam menyelesaikan pekerjaan. Namun masih sangat disayangkan bahwa penggunaan teknologi komputer di PAUD Kabupaten Bekasi sangatlah minim. Hal ini disebabkan oleh keterbatasan pengetahuan teknologi yang dimiliki oleh guru-guru PAUD dan kepala sekolah dalam bidang komputer.

Salah satu hambatan proses belajar mengajar adalah keterbatasaan fasilitas yang dimiliki dan akses terhadap ilmu pengetahuan yang terus berkembang, antara lain keterampilan dalam penggunaan Microsoft Power Point yang terkait dengan proses belajar mengajar. Dalam penerapannya Microsoft Power Point dapat membantu pengajar dalam menyiapkan presentasi bahan ajar kepada siswa-siswi. Oleh karena itu, peguasaan Microsoft Microsoft Power Point sangat penting dalam proses belajar mengajar pada saat ini (Binham, 2014). Namun HIMPAUDI Kabupaten Bekasi saat ini belum memiliki fasilitas 
yang memadai serta para pengajar masih banyak yang belum menguasai Microsoft Power Point, sehingga dapat menjadi kendala dalam menerapkan ilmunya kepada pelajar.

Berdasarkan uraian diatas, maka masalah yang dihadapi oleh guru-guru PAUD se-Kabupaten Bekasi adalah kurangnya penguasaan aplikasi Microsoft Office terutama Microsoft Power Point yang dapat membantu proses belajar mengajar sehingga dapat meningkatkan profesionalisme para guru dalam dunia pendidikan. Selain itu fasilitas sarana pembelajaran seperti komputer perlu ditambah sehingga proses belajar dan mengajar di dalam kelas dapat lebih efektif dan berkualitas.

Sehubungan dengan hal tersebut di atas dan dalam rangka mewujudkan salah satu Tri Dharma Perguruan Tinggi yaitu pengabdian kepada masyarakat, program studi Sistem Informasi Kalbis Institute akan mengusulkan program pelatihan bagi guru-guru PAUD Kabupaten Bekasi tentang Microsoft Power Point. Tujuan pelatihan ini adalah memberikan pengetahuan dasar kepada para pengajar tentang aplikasi komputer Microsoft Microsoft Power Point untuk proses belajar mengajar dalam rangka meningkatkan profesionalisme para guru dalam bidang pendidikan.

\section{METODE PELAKSANAAN}

Sesuai dengan permasalahan diatas, maka kami Dosen Program Studi Sistem Informasi Fakultas Ilmu Komputer dan Ilmu Komunikasi Kalbis Institute akan mengadakan pelatihan dengan tema "Pelatihan Microsoft Power Point Bagi Guru-Guru PAUD Kabupaten Bekasi" pada tanggal 25-26 Agustus 2016 di PKBM Pelita Rahayu Jl. MT.Haryono No.26 Desa Taman Rahayu, Kecamatan Setu, Kabupaten Bekasi, Provinsi Jawa Barat (Kita, 2014).

\section{HASIL DAN PEMBAHASAN}

Deskripsi kegiatan pengabdian kepada masyarakat yaitu pelatihan untuk guru-guru PAUD di Kabupaten Bekasi tanggal 14 Agustus 2014 adalah sebagai berikut:

1. Obeservasi Ke Lokasi Mitra Pengabdian Kepada Masyarakat. Kegiatan observasi pertama kali dilakukan pada tanggal 27 juni 2014. Pada awalnya nya kegiatan ini dimulai dari pembicaraan secara pribadi antara Kordinator PAUD Kecamatan Cikarang Pusat dengan salah satu dosen Program Studi Sistem informasi. Lalu ditindaklanjutin oleh Kalbis Institute melalui observasi untuk identifikasi kondisi serta permasalahan dari mitra. Sehingga dapat diusulkan tema maupun waktu pelaksanaan. Selain itu, dari mitra juga memperkenalkan profil dari HIMPAUDI Kabupaten Bekasi.

2. Perencanaan kegiatan PKM. Setelah diperoleh beberapa informasi dari hasil observasi maka Program Studi Sistem Informasi melaksanakan rapat pada tanggal 08 Juli 2014 pukul 14.00-17.00 di ruang Yudhistira lantai 2. Keluaran dari kegiatan ini adalah rencana topik yang akan diberikan bagi Mitra. Topik yang diputuskan adalah Microsoft Power Point dengan level bagi pemula atau tingkat dasar. Pada kegiatan ini juga disusun materi Microsoft Power Point yang akan diberikan.

3. Rapat Pembagian Tim. Rapat berikutnya yang dilakuan oleh Program Studi adalah rapat pembentukan tim pelatihan Microsoft Power Point yaitu pada tanggal 22 juli 2014 pukul 09.00-12.00 di ruang Yudhistira lantai 2 kampus Kalbis Institute. Selain tim dosen juga dilakukan pembagian materi bagi masing-masing dosen dalam tim. Hasil rapat ditentukan bahwa tim dosen yang akan memberikan pelatihan Microsoft Power Point adalah adalah: Drs. Muhammad Rusli, M.M, dan Edy Winarso, S.Kom., M.M.

4. Kordinasi Dengan Mitra PKM. Setelah ditentukan oleh internal dosen Progrm Studi Sistem Informasi terkait topik, materi serta tim yang terlibat maka tim PKM yang telah dibentuk melakukan pertemuan dengan mitra untuk kordinasi pelaksanaan PKM. Kordinasi meliputi penyampaian materi yang akan disampaikan oleh saat pelaksanaan, rencana waktu pelaksanaan, serta tim dosen yang akan terlibat. Kordinasi dilakukan di Bekasi pada tanggal 26 Juli 2014 pukul 14.00 - 18.00 WIB. Pertemuan pada kegiatan kordinasi juga membahas operasional pelaksanaan kegiatan seperti komsumsi bagi peserta.

5. Rapat Pembuatan proposal. Setelah diperoleh kesepakatan antara mitra dengan tim dosen Program Studi Sistem Informasi maka selanjutnya tim dosen yang terlibat melaksanakan rapat internal untuk penyusunan proposal kegiatan. Rapat pembuatan proposal dilakukan di ruang rapat Yudhistira pukul 14.00 - 17.00 pada tanggal 29 Juli 2014.

6. Pelaksanaan PKM. Kegiatan pelatihan direncanakan selama satu hari hari yaitu tanggal 14 Agustus 2014 pada hari Kamis pukul 08.00-17.00 WIB. Peserta peatihan adalah guru-gur PAUD di Kabupaten Bekasi dengan tim pelatih adalah tim PKM dari dosen-dosen serta mahasiwa Program Studi Sistem Informasi Kalbis Institute. 
Acara dimulai dengan melakukan registrasi peserta pada pukul $08.00-09.00 \mathrm{WIB}$, dilanjutkan pembukaan oleh MC yaitu Ibu Rohmini selaku sekretaris HIMPAUDI Kabupaten Bekasi. Pada acara pembukaan MC memperkenalkan peserta dari 10 kecamatan antara lain Kecamatan Tambun Selatan, Muara Gembong, Tambun Utara, Bojongmangu, Sukawangi, Serang Baru, Cikarang Barat, Cikarang Pusat, Cibarusah, dan Sukatani yang mengikuti acara pelatihan. juga memperkenalkan pengurus HIMPAUDI Kabupaten Bekasi.

09.15 - 09.40 WIB dilanjutkan dengan sambutan oleh Ibu Diana, A.Ks selaku Ketua HIMPAUDI Kabupaten Bekasi. Dalam sambutannya beliau mengucapkan terima kasih atas kehadiran tim PKM Kalbis Insitute dalam membantu upaya meningkatkan kualitas sumber daya manusia dilingkungan Kabupaten Bekasi khususnya adalah guru-guru PAUD Kabupaten Bekasi.

Pukul 09.45 - 10.00 sambutan oleh Ibu Ridha Sefina Samosir, S.Si., M.Kom selaku ketua tim pelaksana PKM. Dalam sambutannya, Ibu Ridha Sefina Samosir, S.Si., M.Kom memperkenalkan kepada peserta pelatihan bahwa kegiatan pengabdian kepada masyarakat merupakan salah satu Tri Dharma Perguruan Tinggi. Beliau juga mengucapkan terima kasih atas kehadiran dan partisipasi guru-guru PAUD di Kabupaten Bekasi yang telah mendukung kegiatan pengabdian kepada masyarakat dengan harapan semoga kegiatan ini nantinya dapat memberikan manfaat bagi para guru dalam meningkatkan kualitas sumber daya manusia dan proses pembelajaran di tempat guru-guru mengajar.

Pukul 10.00 - 12.00 WIB acara dilanjutkan dengan pelatihan dengan tema "Pelatihan Microsoft Power Point Dasar" dengan instruktur Bapak Drs. Muhammad Rusli, MM. Pada modul 1 (langkahlangkah dalam mengoperasikan Microsoft Power Point) pelatihan peserta diperkenalkan dengan aplikasi Microsoft Office untuk membuat bahan ajar yaitu Microsoft Office Power Point Dasar. Pada pelatihan materi yang dibawakan oleh Drs. Muhammad Rusli, MM. adalah: Membuka Power Point; Membuat presentasi baru; Membuat presentasi baru dengan fasilitas template; Menyimpan presentase baru; Membuka presentasi; Menyimpan presentasi yang pernah dibuat dengan nama lain; Menutup presentasi; dan Keluar dari microsft power point

Setelah istirahat untuk makan siang dan ibadah pukul 12.00 - 13.00 WIB acara kembali dilanjutkan dengan pelatihan modul berikutnya. Pukul 13.00 - 15.00 WIB acara dilanjutkan dengan pelatihan
"Pelatihan Microsoft Power Point Dasar" Modul 2 dengan instruktur Bapak Edy Winarso, S.Kom., M.M. Pada modul 2 peserta diperkenalkan dengan aplikasi Microsoft Office Power Point untuk menyunting presentasi. Pada modul 2 materi yang dibawakan oleh Bapak Edy Winarso, S.Kom., M.M. adalah: Memasukan teks kedalam slide; Menambah slide baru; Memilih slide design; Berpindah keslide yang ingin disunting; Mengubah tampilah view; Mengubah normal view ke slide show; Memindahkan urutan slide; Meng-copy slide; Menghapus sebuah slide; Menyisipka slide; Memasukan gambar kedalam slide; Memasukan background ke dalam slide; Memasukan tanggal, number, dan footer kedalam slide; Memasukan table kedalam slide; Memasukan grafik kedalam slide; Mengubah tampilah grafik; Menambah judul grafik; Mem-format tampilan data sheries; dan Memasukan animasi kedalam slide.

Pukul 15.00 - 16.30 WIB acara dilanjutkan dengan pemberian pelatihan yang dipandu oleh Darani Putri (Mahasiwa Prodi Sitem Informasi) dengan instruktur tim dosen yang tergabung kedalam tim PKM secara bergantian. Disini peserta pelatihan juga diberikan kesempatan untuk bertanya mengenai modul pelatihan yang telah diberikan. Pada sesi ini terlihat semua peserta sangat antusisa dengan materi pelatihan yang diberikan. Keingintahuan peserta terlihat dari banyaknya pertanyaan yang diajukan pada sesi ini.

Pukul 16.30 - 16.45 WIB pada akhirnya acara ditutup oleh Ketua Pelaksana PKM yaitu Bapak Muhammad Rusli dan foto bersama. Pukul 16.45 17.00 WIB, dilanjutkan dengan pemberian sertifikat kepada semua peserta. Pelaksanaan kegiatan pelatihan yang dilaksanakan pada tanggal 14 Agustus 2014 pukul 08.00 sampai dengan 17.00 di Gedung PKBM Pelita Rahayu, Jalan MT. Haryono No.26 Desa Taman Rahayu, Kecamatan Setu, Kabupaten Bekasi ditunjukan dengan surat Keterangan No.03/Pelatihan/ Himp.Kab.Bekasi/VIII/2014 yang ditandatangani oleh Ketua Himpunan PAUD (HIMPAUDI) Kabupaten Bekasi yaitu Ibu Diana Rustanti, A.Ks.

\section{SIMPULAN}

Kegiatan pelatihan yang telah dilaksanakan pada tanggal 14 Agustus 2016 dapat disimpulkan bahwa kegiatan pelatihan ini memberikan pengetahuan mengenai aplikasi komputer Microsoft Office Power Point dalam membuat bahan ajar. Para peserta terlihat sangat antusias mengikutinya karena materi pelatihan sesuai dengan kebutuhan peserta. Keingintahuan 
peserta sangat besar, hal ini menjadikan materi pelatihan dapat tersampaikan secara keseluruhan. Nantinya, materi pelatihan ini dapat diterapkan dalam kegaiatan pengajaran sehingga proses belajar dan mengajar dapat lebih efektif dan berkualitas.

Dengan memeperhatikan besarnya minta peserta mengikuti pelatihan ini, maka disarankan untuk dapat diberikan pelatihan lanjutan tentang aplikasi komputer Microsoft Office Power Point dan aplikasi Microsoft Office lainnya, seperti Microsoft Excel dan Microsoft Word agar peserta dapat lebih menguasai aplikasi Micrososft Office. Selain itu, pelatihan dengan tema ini dapat diberikan pada guruguru dari kecamatan lainnya yang belum menguasai aplikasi Micrososft Office.

\section{DAFTAR RUJUKAN}

Binham, B. (2014, March 3). Cara Membuat Template Presentasi Powerpoint Dengan Slide Master. Retrieved April 5, 2014, from Cara Membuat Template Presentasi Powerpoint Dengan Slide Master: https://www. presentasi.net/template-presentasi-powerpoint/

Kita, S. (2014, Januari 5). PKBM PELITA RAHAYU. Retrieved March 15, 2014, from PKBM PELITA RAHAYU: http://sekolah.data.kemdikbud.go.id/index.php/chome/ profil/2D0B933B-2815-433D-8BA5-C112DA0E5E85

Suyadi. (2013). Strategi Pembelajaran Pendidikan Karakter. Bandung: Remaja Rosdakarya. 